\section{HIGH ISOLATION SERIES-SHUNT PHOTOCONDUCTIVE MICROWAVE SWITCH}

Drasko Draskovic, Jean Raphael Olivier Fernandez, and Cesar Briso-Rodriguez

Universidad Politécnica de Madrid, Madrid 28031, Spain;

Corresponding author: drasko.draskovic@upm.es

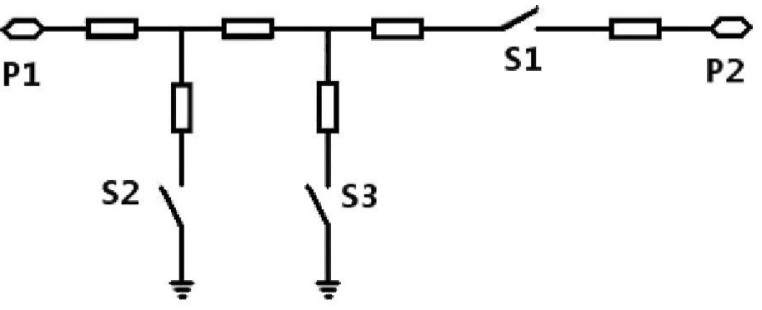

Figure 2 Equivalent circuit of the series-shunt silicon switch

ABSTRACT: This article presents a wide band compact high isolation photoconductive switch, which is based on the series-shunt switch design with three photoconductive switches made of diced high-resistivity silicon wafer placed over a microstrip gap and activated by 808-nm near-infrared laser diodes. The switch shows an insertion loss of $1.2 \mathrm{~dB}$ and an isolation of $44.8 \mathrm{~dB}$ at $2 \mathrm{GHz}$. It is easy to operate and control by light, high-speed, electromagnetically transparent and it does not require any biasing circuits.

\section{INTRODUCTION}

RF and microwave switches are important components in modern wireless circuits and systems. As microwave photonic devices are gaining favor as enabling technologies for future RF and microwave circuits and subsystems, there have been several designs of optically controlled switches proposed recently. The research of optically controlled microstrip switches started in 1970 s $[1,2]$ and is continuing throughout to today. References have reported devices fabricated from coplanar waveguides [3] and microstrip transmission lines printed on silicon substrate [4]. The simple microwave switch [5] was applied in designs of antennas, filters, phase shifters, and couplers [6]. The main advantage of optically controlled microwave circuits is a high level of isolation between the controlling electronic circuit and the microwave circuit. Typically, the highly resistive silicon wafer in these devices is illuminated by a near-infrared laser or a light-emitting diode, with the optical power up to few hundred milliwatts. The devices that have proved themselves ideal for implementation of silicon switches are reconfigurable antennas and cryogenic components [7]. The main advantage in antenna design is the elimination of biasing lines that can interfere with the operation of the antenna, whereas in cryogenic high temperature superconducting devices the thermal energy penetration

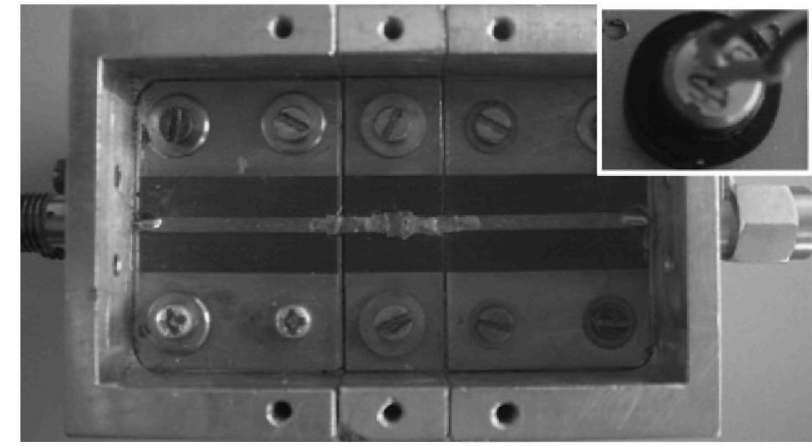

Figure 1 Photograph of a switch prototype in a test circuit with the detail showing the laser diode mounted at the bottom from interface cables becomes critical, so they are usually replaced by optical fibers. Recently, silicon switches have been tested for linearity [8] and switching speed [9], showing promising performance.

One of the disadvantages of photoconductive switches has been their isolation, which usually could not match the isolation achieved by RF microelectromechanical systems (MEMS) switches [8-10]. Most of the applications of switches in mobile and wireless communications systems require them to have both low insertion loss and very high isolation performance. In circuits that use the switches with lower isolation, more intermodulation is produced, which is caused by leakage of signals, and therefore RF performance is degraded. The series/shunt configuration is commonly used in circuits with wideband PIN-diodes, FET switches, and RF MEMS switches. In this article, a seriesshunt silicon photoconductive switch with high isolation characteristic is presented.

\section{SWITCH DESIGN}

Here, we investigate the response of a microwave switch by photodoping the highly resistive semiconductor on the top of the microstrip gap with a $200 \mathrm{~mW} 808-\mathrm{nm}$ near-infrared laser diode and the response of a series-shunt switch configuration. We present a design and experimental demonstration of the active photonic device.

The silicon wafer in test is highly resistive (around 6000 Ohm $\mathrm{cm}^{-1}$ ), type $\mathrm{N}$, doped with phosphorus, with 111 crystal orientation, $0.3-\mathrm{mm}$ thick, single side polished. The other silicon wafers of different characteristics are currently being tested to improve the overall switch characteristics. A series of simulations were performed using Ansoft's HFSS, a three-dimensional electromagnetic solver. During the simulations, a simplified model was used to describe the effect of photodoping [11]. The dice of silicon wafer is considered uniformly illuminated and its permittivity can be expressed according to Drude's formula

S1



Figure 3 Layout of the series-shunt silicon switch 


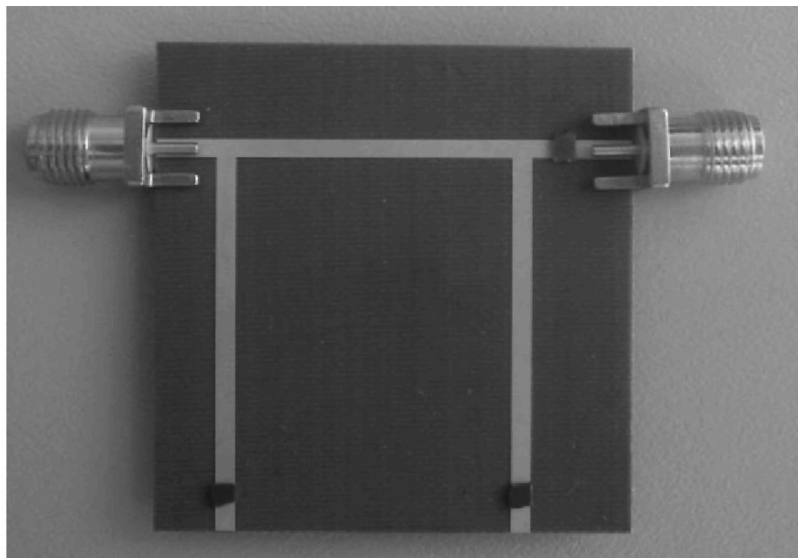

[12]:

Figure 4 Series-shunt switch prototype

$$
\varepsilon_{S i}(e, h)=11.8-\frac{\omega_{p e}^{2}}{\omega^{2}+v_{e}^{2}}\left(1-i \frac{v_{e}}{\omega}\right)-\frac{\omega_{p h}^{2}}{\omega^{2}+v_{h}^{2}}\left(1-i \frac{v_{h}}{\omega}\right),
$$

where $\omega$ is the incident angular frequency $\omega=2 \pi \times 2 \times 10^{9} \mathrm{rad} . \mathrm{s}^{-1}, \omega_{\mathrm{pe}}=(e q)^{1 / 2} /\left(m_{e}^{*} \varepsilon_{0}\right)^{1 / 2}$ is the plasma frequency of the free electrons of density $e$, and effective mass $m_{e}^{*}, m_{e}=0.259, \omega_{\mathrm{ph}}=(h q)^{1 / 2} /\left(m_{h}^{*} \varepsilon_{0}\right)^{1 / 2}$ is the plasma frequency of the holes of density $h$ and effective mass $m_{h}^{*}$, $m_{h}=0.38, v_{e}=4.53 \times 10^{12} s^{-1}$, and $v_{h}=7.71 \times 10^{12} s^{-1}$ are the electron and hole collision frequencies. The corresponding values for the undoped state are $e_{0}=7.7 \times 10^{11} / \mathrm{cm}^{-3}$ and $h_{0}=2.9 \times 10^{8} / \mathrm{cm}^{-3}$.

The sheet conductivity under illumination can be expressed as

$$
\sigma_{s}=\tau_{r} q\left(\mu_{n}+\mu_{p}\right) \frac{P_{0}}{h v}
$$

where $\tau_{r}$ is the effective carrier lifetime, $q$ is the electronic charge, $\mu_{n}$ and $\mu_{p}$ are electron and hole mobilities, $h v$ is the photon energy, and $P_{0}$ is the optical power density.

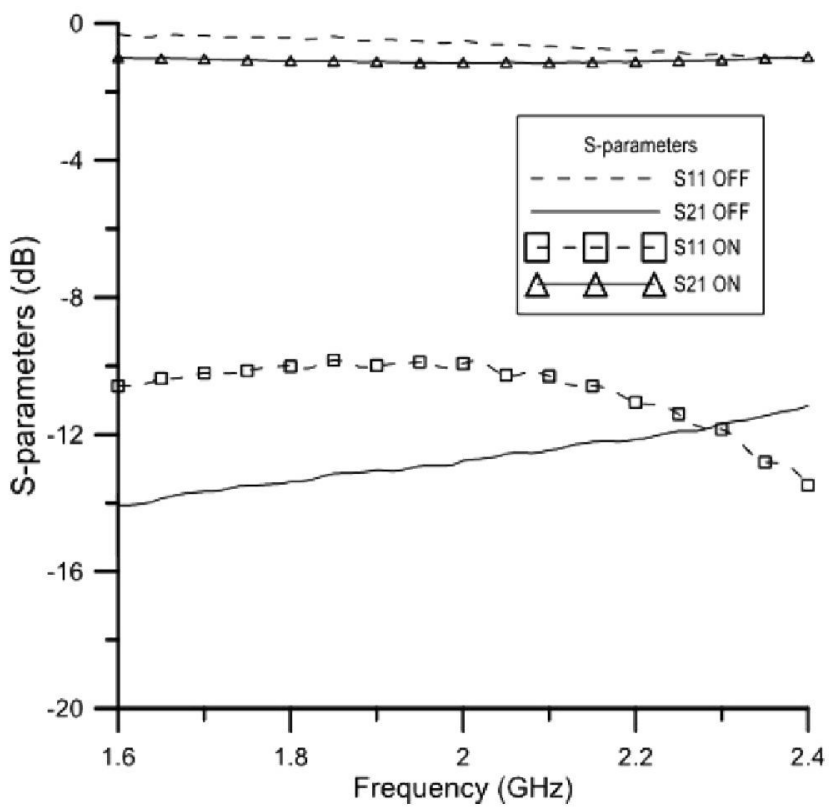

Figure 5 S-parameters of a single switch



Figure $6 S$-parameter simulation of the series-shunt switch in OFF state

The microwave switch shown in Figure 1 operates as an active photonic device by photodoping the highly resistive semiconductor on the top of the microstrip gap with a $200 \mathrm{~mW} 808$ $\mathrm{nm}$ infrared laser diode. The design is based on Taconic TLY-5 substrate, with the dielectric constant 2.2. A $1 \times 1 \mathrm{~mm}^{2}$ dice of silicon wafer is placed over a gap and fixed in place using silver epoxy. The light is focused using a laser diode module with AR-coated glass focusing lens and a small heat sink. The laser diode is mounted at the bottom side and a $0.5-\mathrm{mm}$ hole was drilled in the substrate. The microstrip lines have characteristic impedances of $50 \mathrm{Ohms}$, and the gap width is $0.5 \mathrm{~mm}$.

The proposed configuration uses three identical silicon switches, one series, and two shunt switches as shown in Figure 2. When the series one ( $\mathrm{S} 1)$ is $\mathrm{ON}$ and the shunt two



Figure $7 \quad S$-parameter measurement of the series-shunt silicon switch in OFF state 


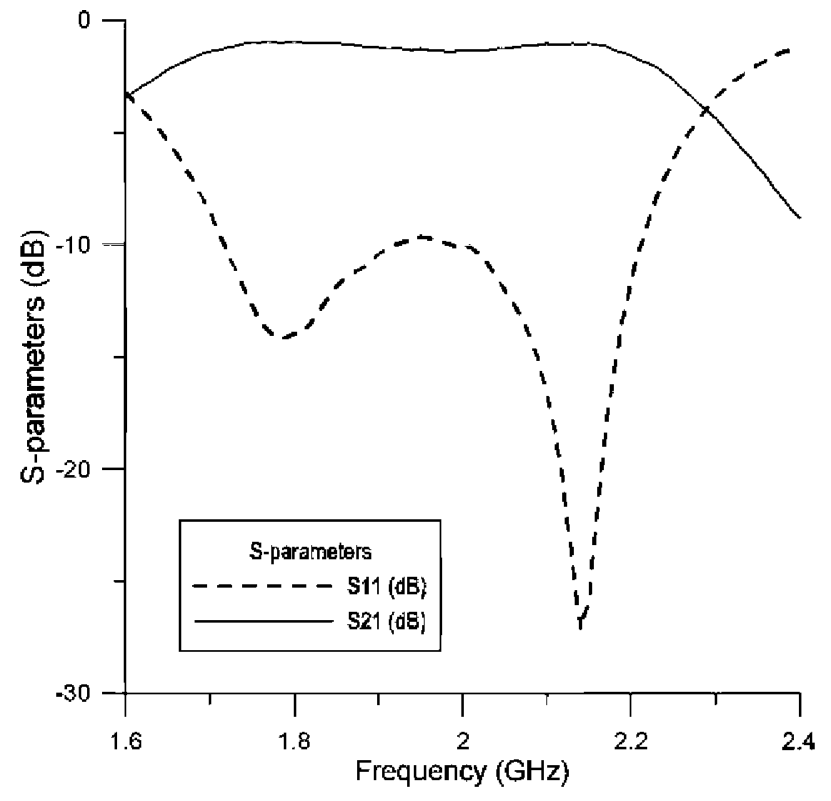

Figure $8 S$-parameter simulation of the series-shunt silicon switch in ON state

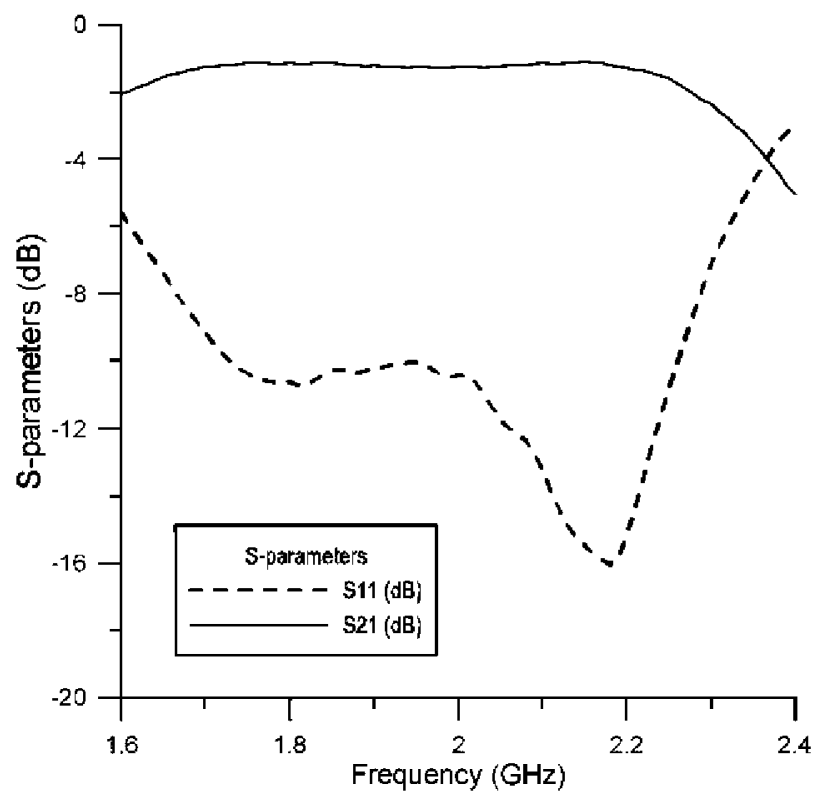

Figure $9 S$-parameter measurement of the series-shunt silicon switch in $\mathrm{ON}$ state

(S2 and S3) are OFF, the series-shunt RF switch is in ON state. On the other hand, when the series one is OFF and the shunt two are ON, it is in OFF state. Quarter-wavelength transmission lines are used to separate switches. This switch design is optimized for a frequency of $2 \mathrm{GHz}$. The layout of the switch is shown in Figure 3. Series-shunt switch prototype is shown in Figure 4 .

\section{SIMULATION AND EXPERIMENTAL RESULTS}

The simulations during the initial phase were performed using Ansoft HFSS. The switch was modeled with different material conductivities for OFF and ON states. The silicon wafer conductivities were chosen as 0.01 and $250 \mathrm{~S} / \mathrm{m}$. These values matched the measured ones from the switch. The measured results of a single switch are shown in Figure 5. They demonstrate insertion loss of $0.84 \mathrm{~dB}$ and isolation of $12.76 \mathrm{~dB}$ at $2 \mathrm{GHz}$.

Simulation and measurement results of the series-shunt switch configuration in OFF state are shown in Figures 6 and 7 , respectively. Simulation and measurement results for ON state are shown in Figures 8 and 9, respectively. The switch shows the insertion loss of $1.2 \mathrm{~dB}$ and the isolation of $44.8 \mathrm{~dB}$. Simulation and measurement results are in good agreement.

\section{CONCLUSION}

A novel structure for a series-shunt switch using silicon switches has been designed and fabricated. The series-shunt switch exhibits an outstanding isolation of more than $40 \mathrm{~dB}$ and a low insertion loss of $1.2 \mathrm{~dB}$ at the operating frequency of $2 \mathrm{GHz}$. The modeled and measured RF performances of the switch are in good agreement. The switch is easy to operate and control by light, high-speed, electromagnetically transparent and it does not require any biasing circuits. It could be integrated into a fully reconfigurable wireless transceiver, enabling components with dynamically programmable parameters to meet the demands of the software-defined radio and cognitive radio systems.

\section{REFERENCES}

1. D.H. Auston, Picosecond optoelectronic switching and gating in silicon, Appl Phys Lett 26 (1975), 101-103

2. W. Platte, Spectral dependence of microwave-power transmission in laser-controlled solid-state microstrip switches, IEE J Solid State Electron Dev 2 (1978), 97-103.

3. J.R. Flemish and R.L. Haupt, Optimization of a photonically controlled microwave switch and attenuator, IEEE Trans Microwave Theory Tech 58 (2010), 2582-2588

4. Y. Horii and M. Tsutsumi, Scattering parameters of semiconductor microstrip line under laser spot illumination, In: 1996 IEEE MTTS International Microwave Symposium Digest, Vol. 1-3, San Francisco, CA 1996, pp. 1675-1678.

5. C.J. Panagamuwa, A. Chauraya, and J.C. Vardaxoglou, Frequency and beam reconfigurable antenna using photoconducting switches, IEEE Trans Antenna Propag 54 (2006), 449-454.

6. D. Draskovic, C. Panagamuwa, J.C. Vardaxoglou, and D. Budimir, Frequency reconfigurable $\mathrm{rf}$ circuits using photoconducting switches, Int J RF Microwave Comput Aid Eng 20 (2010), 15-21.

7. K.F. Raihn, N.O. Fenzi, E.R. Soares, and G.L. Matthaei, An optical switch for high temperature superconducting microwave band reject resonators, In: 1995 IEEE MTT-S International Microwave Symposium Digest, Vol. 1-3, Orlando, FL, 1995, pp. 187-190.

8. E.K. Kowalczuk, C.J. Panagamuwa, R.D. Seager, and J.C. Vardaxoglou, Characterizing the linearity of an optically controlled photoconductive microwave switch, In: Antennas and Propagation Conference (LAPC), 2010 Loughborough, 2010, pp. 597-600.

9. Y. Tawk, S. Hemmady, C.G. Christodoulou, and G. Balakrishnan, Measuring the transition switching speed of a semiconductor-based photoconductive switch using RF techniques, In: Antennas and Propagation (APSURSI), 2011 IEEE International Symposium, Spokane, WA, 2011, pp. 972-975.

10. Y. Kaneko, T. Takenaka, T.S. Low, Y. Kondoh, D.E. Mars, D. Cook, and M. Saito, Microwave switch: LAMPS (light activated microwave photoconductive switch), IEE Electron Lett 39 (2003).

11. A. Degiron, J.J. Mock, and D.R. Smith, Optical control of metamaterial unit cells at microwave frequencies, In: 2007 International Symposium on Signals, Systems and Electronics, Vol. 1 and 2, 2007, pp. 202-205.

12. C.H. Lee, P.S. Mak, and A.P. Defonzo, Optical control of millimeter-wave propagation in dielectric wave-guides, IEEE J Quantum Electron 16 (1980), 277-288. 